\title{
Impact of Physical Activity and Cardiovascular Fitness on Total Homocysteine Concentrations in European Adolescents: The HELENA Study
}

\author{
Jasmin BenseR ${ }^{1,2}$, Jara VAltueÑA ${ }^{1}$, Jonatan R. Ruiz ${ }^{3}$, Juan Mielgo-Ayuso ${ }^{1}$, \\ Christina BREIDENASSEL ${ }^{1,2}$, German VICENTE-RODRIGUEZ ${ }^{4}$, Marika FERRARI ${ }^{5}$, \\ Kurt WidHalm ${ }^{6}$, Yannis MAnios ${ }^{7}$, Michael SjÖSTRÖM ${ }^{8}$, Denes MOLNAR ${ }^{9}$, \\ Sonia GómeZ-Martínez ${ }^{10}$, Antony KAFATOS ${ }^{11}$, Gonzalo PALACIOS ${ }^{1,12}$, Luis A. Moreno ${ }^{4}$, \\ Manuel J. CASTILlo ${ }^{13}$, Peter SteHLE ${ }^{2}$, Marcela GonZÁleZ-Gross ${ }^{1,2,12, *}$, \\ on behalf of the HELENA Study Group ${ }^{\varphi}$ \\ ${ }^{1}$ ImFine Research Group, Department of Health and Human Performance, \\ Technical University of Madrid, Madrid, Spain \\ ${ }^{2}$ Department of Nutrition and Food Sciences-Nutritional Physiology, University of Bonn, Bonn, Germany \\ ${ }^{3}$ PROFITH "PROmoting FITness and Health through physical activity" Research Group, \\ Department of Physical Education and Sport, University of Granada, Granada, Spain \\ ${ }^{4}$ GENUD “Growth, Exercise, Nutrition and Development" Research Group, University of Zaragoza, Spain \\ ${ }^{5}$ Istituto Nazionale di Ricerca per gli Alimenti e la Nutrizione, \\ Applied Science Department INRAN, Rome, Italy \\ ${ }^{6}$ Department of Pediatrics, Private Medical University, Salzburg, Austria \\ ${ }^{7}$ Department of Nutrition and Dietetics, Harokopio University, Athens, Greece \\ ${ }^{8}$ Unit for Preventive Nutrition, Department of Biosciences and Nutrition at NOVUM, \\ Karolinska Institutet, Huddinge, Sweden \\ ${ }^{9}$ Department of Pediatrics, Medical Faculty, University of Pécs, Pécs, Hungary \\ ${ }^{10}$ Immunonutrition Research Group, Department of Metabolism and Nutrition, Institute of Food Science, \\ Technology and Nutrition (ICTAN), Spanish National Research Council (CSIC), Madrid, Spain \\ ${ }^{11}$ University of Crete, School of Medicine, Heraklion, Greece \\ ${ }^{12}$ CIBER: CB12/03/30038 Fisiopatología de la Obesidad y la Nutrición, CIBERobn, \\ Instituto de Salud Carlos III (ISCIII), Spain \\ ${ }^{13}$ Department of Medical Physiology, School of Medicine, University of Granada, Granada, Spain
}

(Received June 9, 2014)

\begin{abstract}
Summary We examined the association of physical activity (PA), cardiovascular fitness (CVF) and fatness with total homocysteine (tHcy) concentrations in European adolescents. The present study comprised 713 European adolescents aged 14.8 \pm 1.2 y (females 55.3\%) from the multicenter HELENA cross-sectional study. PA was assessed through accelerometry, CVF by the 20-m shuttle run test, and body fat by skinfold thicknesses with the Slaughter equation. Plasma folate, cobalamin, and tHcy concentrations were measured. To examine the association of tHcy with PA, CVF, and fatness after controlling for a set of confounders including age, maturity, folate, cobalamin, creatinine, smoking, supplement use, and methylenetetrahydrofolate reductase 677 genotype (CC 47\%, CT 43\%, TT 10\%), bivariate correlations followed by multiple regression models were performed. In the bivariate correlation analysis, tHcy concentrations were slightly negatively correlated $(p<0.05)$ with CVF in females (measured both by stages: $r=-0.118$ and by $\mathrm{VO}_{2}$ max: $r=-0.102$ ) and positively with body mass index $(r=0.100)$. However, daily time spent with moderate and vigorous PA showed a weak positive association with tHcy in females $(p<0.05)$. tHcy concentrations showed a tendency to decrease with increasing CVF and increase with increasing BMI in female European adolescents. However, tHcy concentrations were positively associated with moderate and vigorous PA in female European adolescents.
\end{abstract}

Key Words homocysteine, physical activity, cardiovascular fitness, body constitution

Homocysteine (tHcy) is a sulfur-containing amino acid derived from dietary methionine; its levels are normally maintained within a narrow range by the activity of remethylation and transsulfuration (1). Elevated fasting plasma tHcy concentrations are considered a

\footnotetext{
*To whom correspondence should be addressed.
}

E-mail: marcela.gonzalez.gross@upm.es biomarker of increased oxidative stress, which is associated with an increased risk for endothelial damage and inflammatory vascular processes $(2,3)$. Moreover, tHcy has been suggested to be a continuous independent and modifiable risk factor for several multi-system diseases including cardiovascular diseases (4) and stroke (5); dementia and Alzheimer's disease (6); and osteoporotic fracture (7). 
Individual tHcy concentrations depend on non-communicable factors such as age and gender, showing higher levels in males than females and in older than in younger populations $(8,9)$. In addition, the common C677T polymorphism of the 5,10-methylenetetrahydrofolate reductase (MTHFR) gene, which regulates folate metabolism involved in folate-dependent remethylation of Hcy, has been established as an important genetic determinant of elevated Hcy $(10,11)$.

Lifestyle factors such as excessive alcohol intake, smoking, extenuating physical activity, and hyper-energetic nutrition resulting in obesity as well as folate and vitamin $\mathrm{B}_{12}$ deficiencies, can increase tHcy above adequate concentrations (12-14).

Although it is well established that physical activity (PA) is a key component of good health and disease prevention both in adults (15) and in children and adolescents $(16,17)$, there have been contradictory reports regarding its effects on plasma Hcy, without the type of exercise or intensity to cause changes in tHcy being well defined $(18,19)$. However, PA of moderate and high intensities (>758 min per week) could increase tHcy concentrations due to elevated vitamin requirements (20). These divergences could be due to the different techniques used for evaluation of PA, including self-reported questionnaires, the lack of consideration of intensity or duration of PA, limited statistical power with small sample size, and no adjustment for the potential confounders (4).

Studies examining the possible interplay among PA, cardiovascular fitness (CVF) and fatness with tHcy concentrations in childhood and adolescence are not clear. In a small sample of Spanish adolescents from the AVENA study (Alimentación y Valoración del Estado Nutricional de los Adolescentes) an inverse association between tHcy and CVF was observed in females (21). In contrast, results from the Swedish part of the European Youth Heart Study (EYHS) did not support these previous findings (22). Thus, the purpose of this study was to examine the association of tHcy concentrations with objectively assessed PA, CVF and fatness after controlling for potential confounders in a large sample of European adolescents.

\section{PARTICIPANTS AND METHODS}

Participants, recruitment and study design. The HELENA-CSS study (HEalthy Lifestyle in Europe by Nutrition in Adolescence) was a multi-centre cross-sectional study aiming to obtain reliable and comparable data from a random sample of 3,528 European adolescents of 10 different cities aged between 12.5 and $17.5 \mathrm{y}$ on a broad battery of nutrition and health-related parameters $(23,24)$. Selection of cities was based on two criteria: regional distribution and presence of an active research group assuring sufficient expertise and resources to successfully perform epidemiological studies. Within the study, Stockholm (Sweden) represented Northern Europe, Athens and Heraklion (Greece), Rome (Italy) and Zaragoza (Spain) Southern Europe, Pécs (Hungary) Eastern Europe, Gent (Belgium) and Lille (France)
Western Europe, and Dortmund (Germany) and Vienna (Austria) Central Europe. Reliable and objective data concerning age and gender were obtained by analysing complete school classes. On the city level, diversity of the sample with respect to cultural and socioeconomic aspects was achieved by performing a random proportional distribution of all schools taking into account the site of the school (district/zone of the city) and the type of school (public or private). One partner (Gent) centrally performed for all study centres the school and class random selection procedure, including the subset of classes for blood sampling. In case a selected school refused its participation, a school with comparable characteristics from a list of substitutes was chosen. The sample size of 3,528 adolescents was estimated using body mass index (BMI; confidence level of 95\%, and $\mathrm{a} \pm 0.3$ error). One-third of the classes was randomly selected for blood collection, resulting in a total of 1,089 (53\% females) blood samples for the subsequent clinical biochemistry assays. Sixty-three per cent of the total sample $(n=3,528)$ had valid data on cardiorespiratory fitness and physical activity, resulting in a final sample of 2,213 adolescents (53.8\% females), for whom blood analyses were available for 713 (55.3\% females).

Exclusion criteria were limited to subjects who were not able to speak the local language, subjects participating simultaneously in another clinical trial, subjects aged $<12.5$ or $>17.5 \mathrm{y}$ and subjects having suffered from acute infection $1 \mathrm{wk}$ before the visit. Exclusions from the study were done a posteriori, without the knowledge of the affected subjects, in order to avoid non-desired situations. All protocols and informed consents for this study were reviewed and approved by an Ethics Review Committee in each country according to the Declaration of Helsinki 1964 (revision of Edinburgh 2000), Convention of Oviedo (1997), the Good Clinical Practice, and the legislation about clinical research in humans in each of the participating countries. Informed written consent was obtained from subjects and parents or guardians. A complete description of ethical issues and good clinical practice within the HELENA-CSS is provided elsewhere (25).

Prior to the start of the HELENA-CSS all methods were tested in a pilot study to assure an optimal sampling procedure and to optimise transport logistics and analytics.

Medical examination and blood sampling. Prior to the study day, participants were asked to abstain from eating and drinking after 8 p.m. On the study day, a medical doctor visited the school classes and asked all participants for medical history and acute diseases. A blood sampling questionnaire was used to assess fasting status, acute infections, allergies, smoking, vitamin and mineral supplements, and medication. Maturity was assessed by means of Tanner stage (26). Medical data and all information were recorded in a case report form for each participant.

Blood sampling generally took place between 8 and 10 a.m. Approximately $30 \mathrm{~mL}$ of blood was collected from an antecubital vein in serum and heparin monovettes ${ }^{\circledR}$ 
(Sarstedt AG \& Co., Nümbrecht, Germany). Then, breakfast was offered to all participants.

Sample pre-treatment and transport. The blood sampling procedure within the HELENA-CSS was described in detail by Gonzalez-Gross et al. (27). Briefly, serum gel tubes were centrifuged at 3,500 revolutions per minute (rpm) for $10 \mathrm{~min}$ within $1 \mathrm{~h}$ after blood drawing for measuring creatinine. For the measurement of folate, cobalamin, and tHcy heparin gel tubes were immediately placed on ice and centrifuged at 3,500 rpm for 10 min within 30 min after blood drawing. Within $24 \mathrm{~h}$ the supernatant of heparin was transported at a stable temperature of $4-7^{\circ} \mathrm{C}$ while serum was transported at room temperature to the central laboratory in Bonn. All samples were stored at $-80^{\circ} \mathrm{C}$ until withdrawn for bunched analyses.

Biochemical and genetic analyses. The biochemical analyses of folate, cobalamin, and tHcy were done with the use of Immulite 2000 (DPC Biermann GmbH, Bad Nauheim, Germany). The intra- and interassay coefficients of variation were $5.4 \%$ and $8.1 \%$ for folate, $5.0 \%$ and $12.7 \%$ for cobalamin, and $7.1 \%$ and $10.7 \%$ for tHcy. Creatinine was measured on the Dimension RxL clinical chemistry system (Dade Behring, Schwalbach, Germany) with enzymatic methods using the manufacturer's reagents and instructions. The intraassay coefficient of variation of the creatinine assay was 3.4\%, while the interassay coefficient was $5.8 \%$. The DNA was extracted from white blood cells with the Puregene kit (QIAGEN, Courtaboeuf, France). The SNP MTHFR $677 \mathrm{C} / \mathrm{T}$ was genotyped by Illumina (Eindhoven, Netherlands) with Golden Gate assay with a $100 \%$ success rate. The genotype distribution of the polymorphism respected the Hardy-Weinberg equilibrium $(p=0.17)$ in the sample.

Physical activity. A uni-axial accelerometer (Actigraph $^{\text {TM }}$ GT1M, Pensacola, FL) was used to assess PA. Adolescents were instructed to place the monitor underneath the clothing, at their lower back, using an elastic waist band and to wear it for 7 consecutive days. They were also instructed to wear the accelerometer at all times except during water-based activities and periods of sleep. At least $3 \mathrm{~d}$ of recording with a minimum of $8 \mathrm{~h}$ registration per day was set as an inclusion criterion; the time-sampling interval (epoch) was $15 \mathrm{~s}$. A measure of total volume of activity was expressed as the sum of recorded counts per epoch divided by the total daily registered time in minutes. The time engaged in moderate PA and vigorous PA was calculated and presented as the average time per day during the entire recording. The time engaged at moderate PA [3-6 metabolic equivalents (METs)] was calculated based upon a blanket cut-off of 2,000 counts per minute (cpm)approximately equivalent to the intensity of a brisk walk $(4.5 \mathrm{~km} / \mathrm{h})$. Periods of vigorous PA (>6 METs) were based upon a blanket cut-off of 4,000 cpm. In addition, the time spent in at least moderate intensity level activity (>3 METs) was calculated as the total time spent in moderate and vigorous physical activity (MVPA, min/d). Each minute spent above the specific cut-off was sum- marised in the corresponding intensity level group.

Cardiovascular fitness. CVF was assessed by the 20-m shuttle run test. Adolescents were instructed to run in a straight line and to pace themselves according to the audio signals emitted from a pre-recorded cassette tape. The initial speed was $8.5 \mathrm{~km} / \mathrm{h}$, which was increased by $0.5 \mathrm{~km} / \mathrm{h}$ per minute ( $1 \mathrm{~min}$ equal to one stage). The tape used was calibrated over $1 \mathrm{~min}$. The test was finished when the participant either failed to reach the end lines concurrent with the audio signals on two consecutive occasions or stopped because of fatigue. CVF was recorded as the number of stages completed (precision of 0.5 steps). In addition, to facilitate comparison with previous studies maximal oxygen consumption $\left(\mathrm{VO}_{2} \mathrm{max}, \mathrm{mL} \mathrm{O}_{2} / \mathrm{kg} / \mathrm{min}\right)$ was estimated using the Léger equation (28).

Body composition measurements. The anthropometric methods used within the HELENA-CSS were described by Nagy et al. (29). Briefly, body weight was measured in kg using a standard beam balance (Type SECA 861, UK, precision $100 \mathrm{~g}$, range 0-150 kg). Height was measured in $\mathrm{cm}$ using a precision stadiometer (Type SECA 225, precision $0.2 \mathrm{~cm}$, range $70-200 \mathrm{~cm}$ ). Body mass index was calculated with the equation weight in $\mathrm{kg}$ divided by height in $\mathrm{m}$ squared $\left(\mathrm{kg} / \mathrm{m}^{2}\right)$. Skinfold thickness (triceps, biceps, subscapular, suprailiac, thigh, and calf) was repeatedly measured on the left side of the body using a Holtain caliper (Crymych, UK, range 0-40 mm) and the mean calculated. Only adolescents providing data for the sum of six skinfolds (hereafter referred to as 'skinfold thickness') were included for the analyses. Percent body fat was calculated with the use of the following equation reported by Slaughter et al.: fat $(\%)=0.61 \times($ triceps skinfold in $\mathrm{mm}+$ calf skinfold in $\mathrm{mm})+5.1$ for females and fat $(\%)=0.735 \times$ (triceps skinfold in $\mathrm{mm}+$ calf skinfold in $\mathrm{mm})+1$ for males (30).

Evaluation and statistics analysis. Regarding the point mutation in the MTHFR gene at nucleotide position 677, adolescents were identified as carriers of the homozygous for the wild-type allele (CC), heterozygous (CT), and homozygous for the variant allele genotype. Further, adolescents were classified into supplement users and non-supplement users (questionnaires). Smoking behaviour was categorised into daily smoking, smoking at least once a week but not every day, smoking less than once a week, and non-smokers. The number of cigarettes per day was not considered.

All data analyses were performed by using the Statistical Package for Social Sciences (SPSS) version 19.0 for Windows (SPSS Inc., Chicago, IL). A weighting factor was introduced in order to adjust the theoretical sampling to the observed sample in function of age and gender. Descriptive statistics are shown as mean \pm standard deviation (SD) unless otherwise stated. $p$-values $<0.05$ were considered as statistically significant. Blood tHcy, folate, and cobalamin concentrations, levels of CVF (stages and $\mathrm{VO}_{2} \mathrm{max}$ ), and BMI were normalised by natural logarithm transformation. To test gender-specific differences as well as subgroups with MVPA $<60 \mathrm{~min} / \mathrm{d}$ 
Table 1. Gender-specific characteristics of the HELENA participants.

\begin{tabular}{|c|c|c|c|}
\hline & Male $(n=319)$ & Female $(n=394)$ & $p$-value \\
\hline Age in y $(n)$ & $14.8 \pm 1.2$ & $14.8 \pm 1.1$ & $0.657^{*}$ \\
\hline Maturity in stages $\%$ & & & $0.008^{\#}$ \\
\hline $\mathrm{I} / \mathrm{II} / \mathrm{III} / \mathrm{IV} / \mathrm{V}$ & $1.4 / 7.3 / 19.9 / 37.6 / 33.8$ & $0 / 4.3 / 22.0 / 42.5 / 31.2$ & \\
\hline Body mass index in $\mathrm{kg} / \mathrm{m}^{2}$ & $20.7 \pm 3.3$ & $21.3 \pm 3.4$ & $0.060^{*}$ \\
\hline Skinfold thickness in mm & $75.7 \pm 39.0$ & $103.2 \pm 35.9$ & $<0.001^{*}$ \\
\hline Body fat in $\%$ & $18.4 \pm 9.6$ & $26.1 \pm 7.0$ & $<0.001^{*}$ \\
\hline \multicolumn{4}{|l|}{ MTHFR $677 \mathrm{C} / \mathrm{T}$ in $\%$} \\
\hline $\mathrm{CC} / \mathrm{CT} / \mathrm{TT}$ & $40.1 / 42.5 / 17.4$ & $42.1 / 40.6 / 17.3$ & $0.596 / 0.545 / 0.798^{\#}$ \\
\hline THcy in $\mu \mathrm{mol} / \mathrm{L}$ & $7.6 \pm 4.1$ & $6.8 \pm 2.4$ & $0.005^{*}$ \\
\hline Cobolamin in pmol/L & $336.6 \pm 130.2$ & $360.0 \pm 149.5$ & $<0.001^{*}$ \\
\hline Folate in $\mathrm{nmol} / \mathrm{L}$ & $18.9 \pm 9.7$ & $18.9 \pm 9.7$ & 0.777 \\
\hline Physical activity in counts per minute & $502.8 \pm 168.4$ & $387.0 \pm 122.7$ & $0.049^{*}$ \\
\hline Moderate and vigorous physical activity in min/d & $69.1 \pm 25.0$ & $51.4 \pm 20.4$ & $<0.001^{*}$ \\
\hline Cardiovascular fitness in stages & $7.0 \pm 2.6$ & $3.5 \pm 1.9$ & $<0.001^{*}$ \\
\hline Cardiovascular fitness in $\mathrm{mL} \mathrm{O}_{2} / \mathrm{kg} / \mathrm{min}$ & $52.5 \pm 8.0$ & $36.7 \pm 5.7$ & $<0.001^{*}$ \\
\hline
\end{tabular}

Parameters are shown as mean \pm SD.

* Student's $t$-test.

${ }^{\#} X^{2}$-test.

MTHFR: methylenetetrahydrofolate reductase, CC: homozygous for the wild-type allele, CT: heterozygous, TT: homozygous for the variant-type allele.

Table 2. Bivariate Pearson correlations between homocysteine and independent variables by gender.

\begin{tabular}{|c|c|c|c|c|}
\hline & \multicolumn{2}{|c|}{ Male $(n=319)$} & \multicolumn{2}{|c|}{ Female $(n=394)$} \\
\hline & Pearson & $p$-value & Pearson & $p$-value \\
\hline Physical activity in counts per minute & -0.026 & 0.641 & 0.083 & 0.095 \\
\hline Moderate and vigorous physical activity & -0.103 & 0.069 & 0.080 & 0.120 \\
\hline Cardiovascular fitness in stages & 0.035 & 0.579 & -0.118 & 0.023 \\
\hline Cardiovascular fitness in $\mathrm{mL} \mathrm{O}_{2} / \mathrm{kg} / \mathrm{min}$ & -0.030 & 0.627 & -0.102 & 0.044 \\
\hline Body mass index in $\mathrm{kg} / \mathrm{m}^{2}$ & 0.086 & 0.129 & 0.100 & 0.045 \\
\hline Skinfold thickness in mm & -0.076 & 0.576 & 0.034 & 0.757 \\
\hline Body fat in $\%$ & -0.010 & 0.861 & 0.064 & 0.214 \\
\hline
\end{tabular}

and $\geq 60 \mathrm{~min} / \mathrm{d}$, Student's $t$-test was used for metric variables and the $X^{2}$-test for categorical variables. A bivariate correlation analysis was performed to examine the associations among tHcy and PA (cpm and MVPA), CVF (stages and $\mathrm{VO}_{2} \mathrm{max}$ ), and fatness (BMI, skinfold thickness, and body fat percentage) by gender. Separate multiple regressions were performed by gender to study the relation among tHcy and PA, fitness and fatness after controlling for potential confounders: age, maturity, folate, cobalamin, creatinine, smoking, supplement use, and MTHFR $677 \mathrm{C} / \mathrm{T}$.

\section{RESULTS}

Table 1 reveals the gender-specific characteristics of the study population $(n=713)$. Compared with females $(n=394 ; 55.3 \%)$, males presented significantly higher tHcy and lower cobalamin concentrations (tHcy: males: 7.6 \pm 4.1 vs females: $6.8 \pm 2.4 \mu \mathrm{mol} / \mathrm{L}$ and cobalamin: males: $336.6 \pm 130.2$ vs females: $360.0 \pm 149.5 \mathrm{pmol} / \mathrm{L}$, t-test, $p<0.001$ ), but folate concentrations were similar between genders $(18.9 \pm 9.7 \mathrm{nmol} / \mathrm{L})$. In our sample, $40.1 \%$ of males and $42.1 \%$ of females were CC, $42.5 \%$ of males and $40.6 \%$ of females were CT, and $17.4 \%$ of males and $17.3 \%$ of females were TT. Eleven percent of the adolescents smoked every day, $4 \%$ at least once a week, $5 \%$ less than once a week; $80 \%$ did not smoke. A vitamin and/or mineral supplement was taken by $11 \%$ of the adolescents. Smoking behaviour and supplement use did not vary between genders.

Table 2 presents bivariate Pearson correlations among tHcy concentrations and PA (cpm and MVPA), CVF (stages and $\mathrm{VO}_{2} \max$ ), BMI, skinfold thickness, and body fat. In females, CVF variables (stages: $r=-0.118$ and $\mathrm{VO}_{2}$ max: $\left.r=-0.102\right)$ were negatively and BMI $(r=0.100)$ was positively associated $(p<0.05)$ with tHcy. Table 3 shows the gender-specific relationship among tHcy and PA, fitness, and fatness after controlling for age, maturity, folate, cobalamin, and creatinine concentrations, smoking, supplement use, and MTHFR $677 \mathrm{C} / \mathrm{T}$ polymorphism. In females, tHcy was positively 
Table 3. Standardised multiple regression coefficients $(\beta)$, standard error (SE), and semipartial correlation (sr) examining the association of physical activity, cardiovascular fitness, and fatness with homocysteine after controlling for age, maturity, folate, cobalamin, and creatinine concentrations, smoking, supplement use, and MTHFR 677C/T polymorphism.

\begin{tabular}{|c|c|c|c|c|c|c|c|c|}
\hline & \multicolumn{4}{|c|}{ Males $(n=319)$} & \multicolumn{4}{|c|}{ Females $(n=394)$} \\
\hline & $\beta$ & SE & $\mathrm{sr}$ & $p$-value & $\beta$ & SE & $\mathrm{sr}$ & $p$-value \\
\hline Physical activity in counts per minute & -0.002 & 0.002 & -0.063 & 0.343 & -0.029 & 0.002 & -1.01 & 0.124 \\
\hline Moderate and vigorous physical activity & -0.010 & 0.011 & -0.062 & 0.354 & 0.795 & 0.401 & 0.131 & 0.049 \\
\hline Cardiovascular fitness in stages & 0.015 & 0.008 & 0.128 & 0.051 & -0.278 & 0.345 & -0.053 & 0.222 \\
\hline Cardiovascular fitness in $\mathrm{mL} \mathrm{O}_{2} / \mathrm{kg} / \mathrm{min}$ & -0.246 & 0.149 & -0.019 & 0.100 & 0.096 & 0.107 & 0.059 & 0.370 \\
\hline Body mass index in $\mathrm{kg} / \mathrm{m}^{2}$ & -0.042 & 0.181 & 0.139 & 0.818 & -0.062 & 0.074 & -0.055 & 0.405 \\
\hline Skinfold thickness in mm & -0.042 & 0.000 & -0.055 & 0.585 & -0.012 & 0.000 & -0.011 & 0.864 \\
\hline Body fat in $\%$ & -0.043 & 0.052 & -0.037 & 0.411 & 0.076 & 0.037 & 0.136 & 0.245 \\
\hline
\end{tabular}

associated with PA expressed in MVPA $(p<0.05)$.

Table 4 summarizes results of available studies examining the association of physical activity, cardiovascular fitness, and fatness with homocysteine.

\section{DISCUSSION}

Despite the numerous scientific studies performed in recent years in relation to tHcy and its association with various health indicator outcomes such as PA and CVF, comparable data in the general European adolescent population are scarce. To the best of the authors' knowledge, this is the first study aiming to examine these associations in a large number of individuals of ten different European cities.

The main finding in this study is that after controlling for several potential confounders well established in the literature (age, maturity, folate, cobalamin, creatinine, smoking, supplement use and MTHFR $677 \mathrm{C} / \mathrm{T}$ genotype) (12-14), tHcy levels were significantly influenced by moderate and vigorous PA in female European adolescents. In male European adolescents tHcy levels were not influenced by the studied modifiable factors. Although the associations found are not very strong, these results could help further studies. More studies are needed analysing more deeply the relationship among tHcy, PA and BMI, to be able to establish the clinical relevance. Likewise, it was observed that tHcy levels, PA and CVF in males were significantly higher than in females, while females showed higher cobalamin values than males $(p<0.05)$.

The association between PA and tHcy has been shown in a few studies; most of them were carried out on adults and with equivocal results (31). Duration, intensity, and mode of exercise appear to impact blood tHcy levels differently (4), and may depend on individual fitness levels and MTHFR gene (4). In a recent study with active male subjects (mean age $23.5 \mathrm{y}$ ) tHcy levels significantly increased after both maximal and submaximal acute intensity exercise (32). Regarding children and adolescents, the Swedish part of the EYHS study (children: 9-10 y $(n=301)$ and adolescents: $15-16$ y $(n=379))$ was the first to examine the association between tHcy and PA (22). No significant results were found $(p=0.30)$ for the total sample after adjustment for gender, pubertal development, socioeconomic status, folate intake, cobalamin intake, and MTHFR $677 \mathrm{C} / \mathrm{T}$ genotype, but the results were not split by gender. As our results showed significant tHcy differences by gender, data were analysed separately. A significant positive association between tHcy concentrations and MVPA was found in female adolescents ( $p<0.05$, Table 3$)$, but not in males. These data suggest that tHcy levels could be higher in very active female adolescents.

Fitness is an important marker for several health outcomes in young people like obesity, cardiovascular risk, and skeletal and psychological health (33). CVF is defined as the ability of active skeletal muscle to utilise oxygen during exercise. Changes in tissues and systemic vasculature may deteriorate the physiological capacity and subsequently may also negatively affect CVF. To some extent, elevated tHcy concentrations may contribute to these pathological changes by the generation of reactive oxygen species and impairment of nitric oxide production and bioavailability (3). Regarding adolescents, in previous studies, CVF was significantly and inversely associated with tHcy concentrations in Spanish female adolescents from the AVENA Study $(n=80$

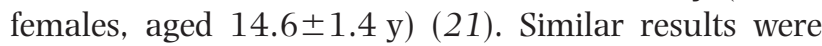
obtained in our study with a larger sample of European female adolescents $(n=394)$, confirming that CVF is a way of not stimulating tHcy metabolism in female adolescents. In contrast, results from the EYHS did not indicate a significant association between tHcy and fitness in children or adolescents (22). The difference between results from the AVENA as well as our study and the Swedish part of the EYHS might be due to the smaller sample size located only in one country. Additionally, it must be considered that healthy children and adolescents usually do not show cardiovascular pathologies.

To encourage an active lifestyle, the World Health Organisation and other international and national public health organisations propose that school-aged children should perform at least 60 min of moderate to vigorous intensity PA each day to ensure a healthy development $(16,34)$. Male adolescents participating in the HELENA-CSS achieved these recommendations with 
Table 4. Summarized results of studies examining the association of physical activity, cardiovascular fitness, and fatness with homocysteine.

\begin{tabular}{|c|c|c|c|}
\hline Author & Methods & Factor & Results (tHcy) \\
\hline $\begin{array}{l}\text { De Laet et al. } \\
1999\end{array}$ & $n=647,5-19 \mathrm{y}$, Belgium, $\mathrm{GM} \pm \mathrm{SD}$ & BMI & n.s. \\
\hline $\begin{array}{l}\text { Gallistl et al. } \\
2001\end{array}$ & $\begin{array}{l}\text { 3-wk weight loss intervention, } 37 \text { obese } \\
\text { females and } 19 \text { obese males, } 11.9 \pm 1.7 \mathrm{y}\end{array}$ & LBM & + , baseline LBM, $p=0.002$ \\
\hline $\begin{array}{l}\text { Bates et al. } \\
2002\end{array}$ & NDNS, $n=1,193,4-18 \mathrm{y}, \mathrm{UK}$ & BMI & n.s. \\
\hline $\begin{array}{l}\text { Shen et al. } \\
2002\end{array}$ & $\begin{array}{l}\text { Taipei Children Heart Study, } n=1,235 \text {, } \\
12-15 \text { y, Taiwan, mean } \pm \text { SD }\end{array}$ & BMI & M: sign. corr. \\
\hline $\begin{array}{l}\text { Randeva et al. } \\
2002\end{array}$ & $\begin{array}{l}\text { intervention, } 21 \text { overweight women with } \\
\text { polycystic ovary syndrome, } 29.7 \pm 6.8 \mathrm{y} \text {, brisk } \\
\text { walking } 3 \times \text { per week over } 6 \text { mo }\end{array}$ & $\mathrm{PA}$ & $\begin{array}{l}\text { baseline: } 10.06 \pm 3.22 \text { vs after exercise: } \\
7.36 \pm 1.96 \mu \mathrm{mol} / \mathrm{L}, p<0.001\end{array}$ \\
\hline Kuo et al. 2005 & $\begin{array}{l}\text { NHANES, } n=1,444,20-49 \mathrm{y} \text {, multiple logistic } \\
\text { regressions, adjustments include folate and } \\
\text { vitamin } \mathrm{B}_{12} \text { concentrations }\end{array}$ & CVF & $\begin{array}{l}\text { as continuous variable }(p=0.003) \text {. } \\
\text { as quartiles }(p<0.001) \\
\text { as odds ratios }(p<0.001)\end{array}$ \\
\hline $\begin{array}{l}\text { Brasileiro et al. } \\
2005\end{array}$ & case control study, $n=239,5-19 \mathrm{y}$, Brazil & BMI & n.s. \\
\hline \multirow[t]{2}{*}{$\begin{array}{l}\text { Mora et al. } \\
2006\end{array}$} & $\begin{array}{l}\text { Women's Health Study, } n=27,158 \text {, } \\
54.7 \pm 7.1 \text { y, quintiles of PA, median }\end{array}$ & $\mathrm{PA}$ & $\begin{array}{l}\text { highest quintile }(>1,574 \mathrm{kcal} / \mathrm{wk}): 10.4 \mathrm{vs} \\
\text { lowest quintile (<145 kcal/wk): } 10.8 \mu \mathrm{mol} / \mathrm{L} \text {, } \\
p<0.001\end{array}$ \\
\hline & & & $\begin{array}{l}\text { odds ratios for the association of quintiles of } \\
\text { PA with tHcy concentrations, n.s. }\end{array}$ \\
\hline $\begin{array}{l}\text { Husemoen et al. } \\
2006\end{array}$ & $\begin{array}{l}\text { general lifestyle intervention, } 1-y \text { follow up, } \\
n=915,30-60 \mathrm{y}\end{array}$ & $\mathrm{PA}$ & n.s. \\
\hline $\begin{array}{l}\text { Huemer et al. } \\
2006\end{array}$ & $n=264,2-17 \mathrm{y}$, Austria, mean \pm SD & BMI & $R=0.09, p=0.001$, after adjustment $p>0.05$ \\
\hline Ruiz et al. 2007 & $\begin{array}{l}\text { AVENA study, } n=156,14.8 \pm 1.4 \mathrm{y} \text {, regression } \\
\text { models included folate and vitamin } \mathrm{B}_{12} \text { levels } \\
\text { as well as MTHFR } 677 \mathrm{C} / \mathrm{T} \text { genotype }\end{array}$ & CVF & - , in females, $p=0.007$ \\
\hline \multirow{3}{*}{$\begin{array}{l}\text { Ruiz et al. } \\
2007 b\end{array}$} & \multirow{3}{*}{$\begin{array}{l}\text { EYHS, } n=680,9-10 \text { and } 15-16 \text { y, adjust- } \\
\text { ments for gender, maturity, socioeconomic sta- } \\
\text { tus, folate and vitamin } B_{12} \text { intake, and MTHFR } \\
677 \mathrm{C} / \mathrm{T} \text { genotype }\end{array}$} & $\mathrm{PA}$ & n.s. \\
\hline & & CVF & n.s. \\
\hline & & BMI & n.s. \\
\hline $\begin{array}{l}\text { Papandreou et } \\
\text { al. } 2007\end{array}$ & $n=524,6-15 \mathrm{y}$, Greece & BMI & n.s. \\
\hline $\begin{array}{l}\text { Joubert et al. } \\
2008\end{array}$ & $\begin{array}{l}\text { less active }(<420 \mathrm{~min} / \mathrm{wk}, n=40) \text { compared } \\
\text { with active }(>420 \mathrm{~min} / \mathrm{wk}, n=36) \text { adults, }\end{array}$ & PA & $\begin{array}{l}\text { low PA: } 7.5 \pm 1.6 \text { vs high PA: } 7.7 \pm 1.6 \mu \mathrm{mol} / \mathrm{L} \text {, } \\
p=0.36\end{array}$ \\
\hline & $26 \pm 5 \mathrm{y}$, mean (range) & & $\begin{array}{l}\text { extremely high PA ( }>750 \mathrm{~min} / \mathrm{wk}, n=11): 8.6 \\
(6.1-12.3) \text { vs extremely low PA }(<130 \mathrm{~min} / \\
\text { wk, } n=9): 6.9(2.9-9.1) \mu \mathrm{mol} / \mathrm{L}, p<0.001\end{array}$ \\
\hline Unt et al. 2008 & $\begin{array}{l}\text { currently active ex-athletes }(n=52) \text { compared } \\
\text { with sedentary ex-athletes }(n=25), 35-62 \mathrm{y}\end{array}$ & CVF & $\begin{array}{l}\text { active: } 9.43 \pm 2.12 \text { vs sedentary: } \\
12.32 \pm 4.49 \mu \mathrm{mol} / \mathrm{L}, p<0.001\end{array}$ \\
\hline $\begin{array}{l}\text { Al-Tahan et al. } \\
2008\end{array}$ & $\begin{array}{l}n=165,13-18.5 \mathrm{y}, \text { Spain, median }(2.5 \text { th }- \\
97.5 \text { th percentile })\end{array}$ & BMI & n.s. \\
\hline $\begin{array}{l}\text { Murakami et al. } \\
2011\end{array}$ & $\begin{array}{l}434 \text { Japanese adults ( } 118 \text { men and } 316 \\
\text { women), 23-85 y }\end{array}$ & PA & $\begin{array}{l}\text { n.s. adjusting for age, sex, and folate intake } \\
\text { between groups according to PA category in all } \\
\text { subjects }\end{array}$ \\
\hline $\begin{array}{l}\text { Maroto-Sánchez } \\
\text { et al. } 2013\end{array}$ & $n=10$, healthy males, $18-28 \mathrm{y}$ & acute PA & $\begin{array}{l}\text { significant increase }(p<0.05) \text { in serum tHcy } \\
\text { concentrations after the maximal and sub- } \\
\text { maximal tests }\end{array}$ \\
\hline
\end{tabular}

PA: physical activity, CVF: cardiovascular fitness, BMI: body mass index, MTHFR: methylenetetrahydrofolate reductase, n.s.: not significant, +: positively associated, - : negatively associated.

69.1 $\pm 25.0 \mathrm{~min} / \mathrm{d}$ of MVPA whereas females did not accomplish it (51.4 $\pm 20.4 \mathrm{~min} / \mathrm{d}$ of MVPA). tHcy concentrations did not vary between groups achieving or not achieving these recommendations, neither in males nor in females.

Regarding body composition, associations between
BMI and tHcy concentrations have been frequently investigated in adolescents as presented in Table 4. Osganian et al. (35) found a positive association between tHcy concentrations and BMI in 3,524 adolescents aged 13-14 y, but after adjustment for potential confounders, particularly blood vitamin concentrations, which 
had the strongest effect, the association was no longer significant. These findings emphasize the importance of adjusting for B-vitamin status when examining associations between tHcy and other parameters. We found a positive association between tHcy and BMI only in females $(p=0.045)$, but adjusting for B-vitamin status and MTHFR $677 \mathrm{C} / \mathrm{T}$ genotype. However, we did not find any association between tHcy concentrations and fatness (expressed as skinfold thickness and\% body fat). These results are in accordance with findings reported by several European cross-sectional studies including the EYHS (22), the British National Diet and Nutrition Survey $(n=922,4-18$ y) (36), a Belgian $(n=647$, 5-19 y) (37), a Spanish $(n=165,13-18.5$ y) (38) and a Greek study ( $n=524,6-15$ y) (39), as well as a Brazilian case control study ( $n=239,5-19$ y) (40).

The cross-sectional design of the HELENA study does not allow the drawing of causal conclusions. Some prospective longitudinal studies on the development of cardiovascular risk factors from adolescence to adulthood have been implemented; however, to date most of these studies omitted the relatively new risk factor homocysteine.

Strengths of the present study are the inclusion of a relatively large number of adolescents and several potential confounders including the MTHFR $677 \mathrm{C} / \mathrm{T}$ genotype. PA was objectively measured with accelerometers as well as CVF being objectively measured by the 20-m shuttle run test, and therewith $\mathrm{VO}_{2}$ max was estimated for a better comparability with other studies. The indirect measurement of $\mathrm{VO}_{2}$ max is feasible within epidemiologic studies: it is not only practical, time-efficient, and low in cost and equipment requirements, but can also be performed on large numbers of adolescents simultaneously (41). In addition to BMI, body composition was measured by skinfold thickness which is suggested to be a better predictor of body fatness in later life than BMI (42).

In conclusion, the results of the present study suggest that tHcy concentrations decrease with increasing CVF and increase with increasing BMI in European female adolescents. Additionally, tHcy concentrations were positively associated with moderate and vigorous PA in female European adolescents. However, these associations are weak and probably not relevant in clinical practice. Likewise, variation in tHcy concentrations could not be explained by PA expressed in cpm, CVF, or parameters of fatness in males. All in all, our results confirm the equivocal relationship between tHcy concentrations and exercise, which must be further studied.

\section{Disclosure}

The content of this paper reflects only the authors' view and the rest of HELENA study members are not responsible for it. The writing group takes sole responsibility for the content of this article.

\section{Acknowledgments}

The HELENA study has taken place with the financial support of the European Community Sixth RTD Frame- work Programme (Contract FOOD-CT-2005-007034). Additional support came in the form of by grants from the Spanish Ministry of Education (EX-2007-1124, EX-2008-0641, AP2006-02464; AGL2007-29784-E/ ALI; AP-2005-3827), the Spanish Ministry of Economy and Competitiveness (RYC-2010-05957), Universidad Politécnica de Madrid (CH/018/2008), Swedish Council for Working Life and Social Research, the ALPHA study, a European Union-funded study, in the framework of the Public Health Programme (Ref: 2006120), and the Spanish Ministry of Health: Maternal, Child Health and Development Network (number RD08/0072). The content of this article reflects only the authors' views, and the European Community is not liable for any use that may be made of the information contained therein.

The authors wish to thank Ms Petra Pickert for her contribution to laboratory work.

None of the authors had any conflict of interests.

Contributions of each author: MMG, LAM, MS, MJC, DM, KW, YM, PS and AK are co-responsible of the design of the HELENA study. JRR, MJC, MGG and JB are responsible for the design of the present study. JB, JRR, GP and JMA are responsible for statistical analysis. JB, JV, JRR, JMA, MGG, PS, GVR, MF, CB, GP and SGM are responsible for the first writing of the manuscript. All authors contributed to the execution of the HELENA CSS study, the data analysis and interpretation, and approved the manuscript in its current version.

\section{${ }^{\varphi}$ HELENA Study Group \\ Co-ordinator: Luis A. Moreno.}

Core Group members: Luis A. Moreno, Fréderic Gottrand, Stefaan De Henauw, Marcela González-Gross, Chantal Gilbert.

Steering Committee: Anthony Kafatos (President), Luis A. Moreno, Christian Libersa, Stefaan De Henauw, Jackie Sánchez, Fréderic Gottrand, Mathilde Kersting, Michael Sjöstrom, Dénes Molnár, Marcela González-Gross, Jean Dallongeville, Chantal Gilbert, Gunnar Hall, Lea Maes, Luca Scalfi.

Project Manager: Pilar Meléndez.

1. Universidad de Zaragoza (Spain). Luis A. Moreno, Jesús Fleta, José A. Casajús, Gerardo Rodríguez, Concepción Tomás, María I. Mesana, Germán Vicente-Rodríguez, Adoración Villarroya, Carlos M. Gil, Ignacio Ara, Juan Revenga, Carmen Lachen, Juan Fernández Alvira, Gloria Bueno, Aurora Lázaro, Olga Bueno, Juan F. León, Jesús Ma Garagorri, Manuel Bueno, Juan Pablo Rey López, Iris Iglesia, Paula Velasco, Silvia Bel.

2. Consejo Superior de Investigaciones Científicas (Spain). Ascensión Marcos, Julia Wärnberg, Esther Nova, Sonia Gómez-Martínez, Esperanza Ligia Díaz, Javier Romeo, Ana Veses, Mari Angeles Puertollano, Belén Zapatera, Tamara Pozo.

3. Université de Lille 2 (France). Laurent Beghin, Christian Libersa, Frédéric Gottrand, Catalina Iliescu, Juliana Von Berlepsch.

4. Research Institute of Child Nutrition Dortmund, Rheinische Friedrich-Wilhelms-Universität Bonn (Germany). Mathilde Kersting, Wolfgang Sichert-Hellert, Ellen 
Koeppen.

5. Pécsi Tudományegyetem (University of Pécs) (Hungary). Dénes Molnar, Eva Erhardt, Katalin Csernus, Katalin Török, Szilvia Bokor, Mrs. Angster, Enikö Nagy, Orsolya Kovács, Judit Répasi.

6. University of Crete School of Medicine (Greece). Anthony Kafatos, Caroline Codrington, María Plada, Angeliki Papadaki, Katerina Sarri, Anna Viskadourou, Christos Hatzis, Michael Kiriakakis, George Tsibinos, Constantine Vardavas Manolis Sbokos, Eva Protoyeraki, Maria Fasoulaki.

7. Institut für Ernährungs- und Lebensmittelwissenschaften-Ernährungphysiologie, Rheinische Friedrich Wilhelms Universität (Germany). Peter Stehle, Klaus Pietrzik, Marcela González-Gross, Christina Breidenassel, Andre Spinneker, Jasmin Al-Tahan, Miriam Segoviano, Anke Berchtold, Christine Bierschbach, Erika Blatzheim, Adelheid Schuch, Petra Pickert.

8. University of Granada (Spain). Manuel J. Castillo Garzón, Ángel Gutiérrez Sáinz, Francisco B. Ortega Porcel, Jonatan Ruiz Ruiz, Enrique García Artero, Vanesa España Romero, David Jiménez Pavón, Cristóbal Sánchez Muñoz, Victor Soto, Palma Chillón, Jose M. Heredia, Virginia Aparicio, Pedro Baena, Claudia M. Cardia, Ana Carbonell.

9. Istituto Nazionalen di Ricerca per gli Alimenti $e$ la Nutrizione (Italy). Davide Arcella, Elena Azzini, Emma Barrison, Noemi Bevilacqua, Pasquale Buonocore, Giovina Catasta, Laura Censi, Donatella Ciarapica, Paola D’Acapito, Marika Ferrari, Myriam Galfo, Cinzia Le Donne, Catherine Leclercq, Giuseppe Maiani, Beatrice Mauro, Lorenza Mistura, Antonella Pasquali, Raffaela Piccinelli, Angela Polito, Raffaella Spada, Stefania Sette, Maria Zaccaria.

10. University of Napoli "Federico II" Dept of Food Science (Italy). Luca Scalfi, Paola Vitaglione, Concetta Montagnese.

11. Ghent University (Belgium). Ilse De Bourdeaudhuij, Stefaan De Henauw, Tineke De Vriendt, Lea Maes, Christophe Matthys, Carine Vereecken, Mieke de Maeyer, Charlene Ottevaere, Inge Huybrechts.

12. Medical University of Vienna (Austria). Kurt Widhalm, Sabine Dietrich.

13. Harokopio University (Greece). Yannis Manios, Eva Grammatikaki, Zoi Bouloubasi, Tina Louisa Cook, Sofia Eleutheriou, Orsalia Consta, George Moschonis, Ioanna Katsaroli, George Kraniou, Stalo Papoutsou, Despoina Keke, Ioanna Petraki, Elena Bellou, Sofia Tanagra, Kostalenia Kallianoti, Dionysia Argyropoulou, Katerina Kondaki, Stamatoula Tsikrika, Christos Karaiskos.

14. Institut Pasteur de Lille (France). Jean Dallongeville, Aline Meirhaeghe.

15. Karolinska Institutet (Sweden). Michael Sjöstrom, Patrick Bergman, María Hagströmer, Lena Hallström, Mårten Hallberg, Eric Poortvliet, Julia Wärnberg, Nico Rizzo, Linda Beckman, Anita Hurtig Wennlöf, Emma Patterson, Lydia Kwak, Lars Cernerud, Per Tillgren, Stefaan Sörensen.

16. Asociación de Investigación de la Industria Agroalimentaria (Spain). Jackie Sánchez-Molero, Elena Picó,
Maite Navarro, Blanca Viadel, José Enrique Carreres, Gema Merino, Rosa Sanjuán, María Lorente, María José Sánchez, Sara Castelló.

17. Campden BRI (United Kingdom). Chantal Gilbert, Sarah Thomas, Elaine Allchurch, Peter Burguess.

18. SIK-Institutet foer Livsmedel och Bioteknik (Sweden). Gunnar Hall, Annika Astrom, Anna Sverkén, Agneta Broberg.

19. Meurice Recherche E Development asbl (Belgium). Annick Masson, Claire Lehoux, Pascal Brabant, Philippe Pate, Laurence Fontaine.

20. Campden E Chorleywood Food Development Institute (Hungary). Andras Sebok, Tunde Kuti, Adrienn Hegyi.

21. Productos Aditivos SA (Spain). Cristina Maldonado, Ana Llorente.

22. Cárnicas Serrano SL (Spain). Emilio García.

23. Cederroth International $A B$ (Sweden). Holger von Fircks, Marianne Lilja Hallberg, Maria Messerer

24. Lantmännen Food RED (Sweden). Mats Larsson, Helena Fredriksson, Viola Adamsson, Ingmar Börjesson.

25. European Food Information Council (Belgium). Laura Fernández, Laura Smillie, Josephine Wills.

26. Universidad Politécnica de Madrid (Spain). Marcela González-Gross, Jara Valtueña, Raquel PedreroChamizo, Gonzalo Palacios, Agustín Meléndez, Pedro J. Benito, Juan José Gómez Lorente, David Cañada, Alejandro Urzanqui, Juan Carlos Ortiz, Francisco Fuentes, David Jiménez-Pavón, Ulrike Albers, Juan Mielgo Ayuso, Rosa María Torres, Paloma Navarro.

\section{REFERENCES}

1) Castro R, Rivera I, Blom H, Jakobs C, de Almeida IT. 2006. Homocysteine metabolism, hyperhomocysteinaemia and vascular disease: An overview. J Inherit Metab Dis 29: 3-20.

2) Mangoni AA, Woodman RJ. 2011. Homocysteine and cardiovascular Risk: An old foe creeps back. J Am Coll Cardiol 58: 1034-1035.

3) Papatheodorou L, Weiss N. 2007. Vascular oxidant stress and inflammation in hyperhomocysteinemia. Antioxidants Redox Signaling 9: 1941-1958.

4) Murakami H, Iemitsu M, Sanada K, Gando Y, Ohmori Y, Kawakami R, Sasaki S, Tabata I, Miyachi M. 2011. Associations among objectively measured physical activity, fasting plasma homocysteine concentration, and MTHFR C677T genotype. Eur J Appl Physiol 111: 2997-3005.

5) Saposnik G, Ray JG, Sheridan P, McQueen M, Lonn E, Heart Outcomes Prevention Evaluation 2 Investigators. 2009. Homocysteine-lowering therapy and stroke risk, severity, and disability: Additional findings from the HOPE 2 trial. Stroke 40: 1365-1372.

6) Haan MN, Miller JW, Aiello AE, Whitmer RA, Jagust WJ, Mungas DM, Allen LH, Green R. 2007. Homocysteine, B vitamins, and the incidence of dementia and cognitive impairment: Results from the Sacramento area latino study on aging. Am J Clin Nutr 85: 511-517.

7) Gjesdal CG, Vollset SE, Ueland PM, Refsum H, Meyer HE, Tell GS. 2007. Plasma homocysteine, folate, and vitamin B12 and the risk of hip fracture: The hordaland homo- 
cysteine study. J Bone Mineral Res 22: 747-756.

8) González-Gross M, Marcos A, Pietrzik K. 2001. Nutrition and cognitive impairment in the elderly. Br J Nutr 86: $313-321$.

9) Papoutsakis C, Yiannakouris N, Manios Y, Papaconstantinou E, Magkos F, Schulpis K, Zampelas A, Matalas A. 2006. The effect of MTHFR (C677T) genotype on plasma homocysteine concentrations in healthy children is influenced by gender. Eur J Clin Nutr 60: 155-162.

10) Hustad S, Midttun Ø, Schneede J, Vollset SE, Grotmol T, Ueland PM. 2007. The methylenetetrahydrofolate reductase $677 \mathrm{C} \rightarrow \mathrm{T}$ polymorphism as a modulator of a $\mathrm{B}$ vitamin network with major effects on homocysteine metabolism. Am J Human Genet 80: 846-855.

11) Yang QH, Botto LD, Gallagher M, Friedman JM, Sanders CL, Koontz D, Nikolova S, Erickson JD, Steinberg K. 2008. Prevalence and effects of gene-gene and genenutrient interactions on serum folate and serum total homocysteine concentrations in the united states: Findings from the third national health and nutrition examination survey DNA bank. Am J Clin Nutr 88: 232-246.

12) Jacques PF, Bostom AG, Wilson PW, Rich S, Rosenberg IH, Selhub J. 2001. Determinants of plasma total homocysteine concentration in the Framingham Offspring cohort. Am J Clin Nutr 73: 613-621.

13) Silaste M, Rantala M, Alfthan G, Aro A, Kesäniemi YA. 2003. Plasma homocysteine concentration is decreased by dietary intervention. Br J Nutr 89: 295-301.

14) Selhub J, Jacques PF, Wilson PW, Rush D, Rosenberg IH. 1993. Vitamin status and intake as primary determinants of homocysteinemia in an elderly population. JAMA 270: 2693-2698.

15) Pedersen BK, Saltin B. 2006. Evidence for prescribing exercise as therapy in chronic disease. Scand J Med Sci Sports 16: 3-63.

16) Strong WB, Malina RM, Blimkie CJ, Daniels SR, Dishman RK, Gutin B, Hergenroeder AC, Must A, Nixon PA, Pivarnik JM. 2005. Evidence based physical activity for school-age youth. J Pediatr 146: 732-737.

17) Cuenca-García M, Ortega F, Ruiz J, González-Gross M, Labayen I, Jago R, Martínez-Gómez D, Dallongeville J, Bel-Serrat S, Marcos A. 2012. Combined influence of healthy diet and active lifestyle on cardiovascular disease risk factors in adolescents. Scand J Med Sci Sports 3: 553-562.

18) Herrmann M, Wilkinson J, Schorr H, Obeid R, Georg T, Urhausen A, Scharhag J, Kindermann W, Herrmann W. 2003. Comparison of the influence of volume-oriented training and high-intensity interval training on serum homocysteine and its cofactors in young, healthy swimmers. Clin Chem Lab Med 41: 1525-1531.

19) Borrione P, Rizzo M, Spaccamiglio A, Salvo RA, Dovio A, Termine A, Parisi A, Fagnani F, Angeli A, Pigozzi F. 2008. Sport-related hyperhomocysteinaemia: A putative marker of muscular demand to be noted for cardiovascular risk. Br J Sports Med 42: 894-900.

20) Joubert LM, Manore MM. 2008. The role of physical activity level and B-vitamin status on blood homocysteine levels. Med Sci Sports Exerc 40: 1923-1931.

21) Ruiz JR, Sola R, Gonzalez-Gross M, Ortega FB, VicenteRodriguez G, Garcia-Fuentes M, Gutierrez A, Sjöström M, Pietrzik K, Castillo MJ. 2007. Cardiovascular fitness is negatively associated with homocysteine levels in female adolescents. Arch Pediatr Adolesc Med 161: 166-171.
22) Ruiz JR, Hurtig-Wennlöf A, Ortega FB, Patterson E, Nilsson TK, Castillo MJ, Sjöström M. 2007. Homocysteine levels in children and adolescents are associated with the methylenetetrahydrofolate reductase $677 \mathrm{C}>$ $\mathrm{T}$ genotype, but not with physical activity, fitness or fatness: The European Youth Heart Study. Br J Nutr 97: 255-262.

23) De Henauw S, Gottrand F, De Bourdeaudhuij I, Gonzalez-Gross M, Leclercq C, Kafatos A, Molnar D, Marcos A, Castillo M, Dallongeville J. 2007. Nutritional status and lifestyles of adolescents from a public health perspective. the HELENA Project-Healthy lifestyle in Europe by nutrition in adolescence. J Public Health 15: 187-197.

24) Moreno L, De Henauw S, Gonzalez-Gross M, Kersting M, Molnar D, Gottrand F, Barrios L, Sjöström M, Manios Y, Gilbert C. 2008. Design and implementation of the healthy lifestyle in Europe by nutrition in adolescence cross-sectional study. Int J Obes 32: S4-S11.

25) Beghin L, Castera M, Manios Y, Gilbert C, Kersting M, De Henauw S, Kafatos A, Gottrand F, Molnar D, Sjöström M. 2008. Quality assurance of ethical issues and regulatory aspects relating to good clinical practices in the HELENA cross-sectional study. Int J Obes 32: S12-S18.

26) Tanner JM, Whitehouse RH. 1976. Clinical longitudinal standards for height, weight, height velocity, weight velocity, and stages of puberty. Arch Dis Child $\mathbf{5 1}$ : 170-179.

27) Gonzalez-Gross M, Breidenassel C, Gómez-Martínez S, Ferrari M, Beghin L, Spinneker A, Diaz L, Maiani G, Demailly A, Al-Tahan J. 2008. Sampling and processing of fresh blood samples within a European multicenter nutritional study: Evaluation of biomarker stability during transport and storage. Int J Obes 32: S66-S75.

28) Leger L, Mercier D, Gadoury C, Lambert J. 1988. The multistage 20 metre shuttle run test for aerobic fitness. J Sports Sci 6: 93-101.

29) Nagy E, Vicente-Rodriguez G, Manios Y, Beghin L, Iliescu C, Censi L, Dietrich S, Ortega F, De Vriendt T, Plada M. 2008. Harmonization process and reliability assessment of anthropometric measurements in a multicenter study in adolescents. Int J Obes 32: S58-S65.

30) Slaughter MH, Lohman TG, Boileau RA, Horswill CA, Stillman RJ, Van Loan MD, Bemben DA. 1988. Skinfold equations for estimation of body fatness in children and youth. Hum Biol 60: 709-723.

31) Joubert LM, Manore MM. 2006. Exercise, nutrition, and homocysteine. Int J Sport Nutr Exerc Metab 16: 341-361.

32) Maroto-Sánchez B, Valtueña J, Albers U, Benito PJ, González-Gross M. 2013. El ejercicio agudo aumenta las concentraciones de homocisteína en varones físicamente activos. Nutrición Hospitalaria 28: 325-332.

33) Ortega F, Ruiz J, Castillo M, Sjöström M. 2008. Physical fitness in childhood and adolescence: A powerful marker of health. Int J Obes 32: 1-11.

34) Haskell WL, Lee IM, Pate RR, Powell KE, Blair SN, Franklin BA, Macera CA, Heath GW, Thompson PD, Bauman A. 2007. Physical activity and public health: Updated recommendation for adults from the American College of Sports Medicine and the American Heart Association. Med Sci Sports Exerc 39: 1423-1434.

35) Osganian SK, Stampfer MJ, Spiegelman D, Rimm E, Cutler JA, Feldman HA, Montgomery DH, Webber LS, Lytle LA, Bausserman L. 1999. Distribution of and factors associated with serum homocysteine levels in children: 
Child and adolescent trial for cardiovascular health. JAMA 281: 1189-1196.

36) Bates CJ, Mansoor MA, Gregory J, Pentiev K, Prentice A. 2002. Correlates of plasma homocysteine, cysteine and cysteinyl-glycine in respondents in the British national diet and nutrition survey of young people aged 4-18 years, and a comparison with the survey of people aged 65 years and over. Br J Nutr 87: 71-79.

37) De Laet C, Wautrecht JC, Brasseur D, Dramaix M, Boeynaems JM, Decuyper J, Kahn A. 1999. Plasma homocysteine concentration in a Belgian school-age population. Am J Clin Nutr 69: 968-972.

38) Al-Tahan J, Sola R, Ruiz JR, Breidenassel C, Garcia-Fuentes M, Moreno LA, Castillo M, Pietrzik K, Gonzalez-Gross M. 2008. Methylenetetrahydrofolate reductase $677 \mathrm{CT}$ polymorphism and cobalamin, folate, and homocysteine status in spanish adolescents. Ann Nutr Metab 52: 315-321.

39) Papandreou D, Rousso I, Makedou A, Arvanitidou M,
Mavromichalis I. 2007. Association of blood pressure, obesity and serum homocysteine levels in healthy children. Acta Paediatrica 96: 1819-1823.

40) Brasileiro R, Escrivao M, Taddei J, D'Almeida V, Ancona López F, Carvalhaes J. 2005. Plasma total homocysteine in Brazilian overweight and non-overweight adolescents: A case-control study. Nutrición Hospitalaria 20: 313-319.

41) Ruiz JR, Ortega FB, Gutierrez A, Meusel D, Sjöström M, Castillo MJ. 2006. Health-related fitness assessment in childhood and adolescence: A European approach based on the AVENA, EYHS and HELENA studies. J Public Health 14: 269-277.

42) Nooyens AC, Koppes LL, Visscher TL, Twisk JW, Kemper HC, Schuit AJ, van Mechelen W, Seidell JC. 2007. Adolescent skinfold thickness is a better predictor of high body fatness in adults than is body mass index: The Amsterdam growth and health longitudinal study. Am J Clin Nutr 85: 1533-1539. 